Editorial

\title{
Special Issue on Current Challenges in Materials Design
}

\author{
${ }^{1}$ Chiara Bedon, ${ }^{2}$ Fausto Mistretta, ${ }^{2}$ Mauro Sassu and ${ }^{2}$ Flavio Stochino \\ ${ }^{1}$ Department of Engineering and Architecture, University of Trieste, Trieste, Italy \\ ${ }^{2}$ Department of Civil Environmental Engineering and Architecture, University of Cagliari, Cagliari, Italy
}

Corresponding Author: Flavio Stochino, University of Cagliari, Italy, Email: fstochino@unica.it

\section{Editorial}

This special issue of the International Journal of Structural Glass and Advanced Materials Research contains new contributions and the extended version of some selected papers presented in the 6th International Workshop on Design in Civil and Environmental Engineering (DCEE2017) held at the University of Cagliari during November 9 - 10 - 11, 2017, see Fig. 1. Previous conferences of this series have been successfully held in Rome (2016), Taiwan (2015), Lyngby (2014), Worcester (2013), Dajeon (2011).

DCEE2017 continued the primary objective of exploring what design means within Civil and Environmental Engineering and discussing interdisciplinary design in co-operation with Architecture, Urban Planning, Topography and more.

In this way, one of the main themes of DCEE2017 was the design of new engineered materials. Hussein et al. (2018) presented an innovative technique based on photoacoustic to prepare Porous Silicon p-type. Zhang and Bedon (2018) reported on the use of structural glass for windows and façades under blast loads.

Valdes et al. (2018) analysed the opportunity to recycle plastic elements transforming in a new construction component. Furthermore, interdisciplinary challenges in engineering design was another key topic of the conference. In this special issue we collected several interesting contributions on this theme. Froli and Laccone (2018) discussed an innovative application of integrated multifunctional hybrid glass-steel structure, see Fig. 2.

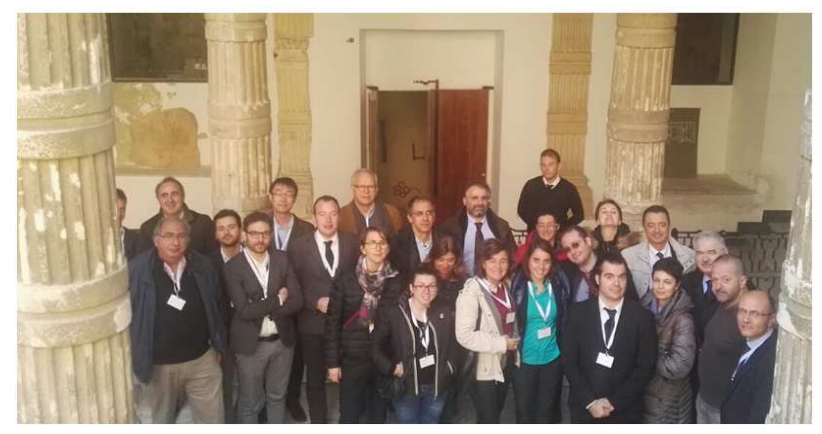

Fig. 1: Delegates at DCEE2017
Akhoundi et al. (2018) analysed the use of glass fiber shear connectors in Textile Reinforced Mortar (TRM), see Fig. 3. This technique can be useful to reduce the vulnerability of masonryinfills to seismicactions.

Zucca et al. (2018) discussed the structural design of an important complex building in Milan. Baraldi et al. (2018) presented a significant numerical approach for non linear problems of soil-structure interaction.

Many presentations of DCEE2017 were focused on the investigation of existing structure throughout non destructive methods. Concu et al. (2018) discussed the Italian standard framework reporting two interesting case studies, while Casapulla et al. (2018) analysed the effectiveness of the infrared thermography to characterize painted vaults in masonry building.

Finally, another session of the conference was devoted to design education in engineering design. A precious contribution was given in Deligia et al. (2018), in which an innovative structural design workshop at the University of Cagliari for engineering bachelor students was reported.

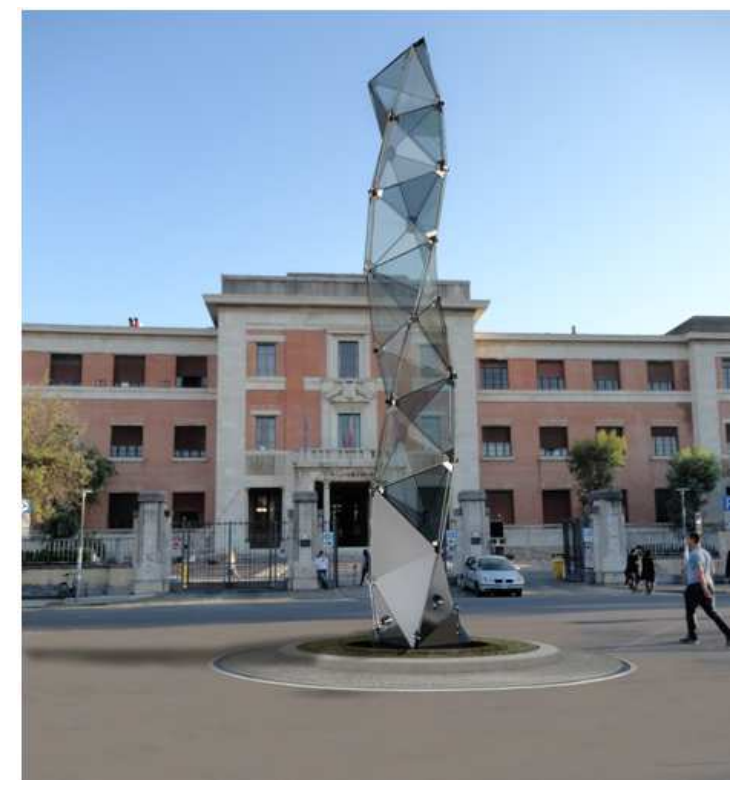

Fig. 2:Example of 15.00 meters tall HYGLASS installed at a roundabout in front of the School of Engineering main building (Pisa), taken from Froli and Laccone (2018) 


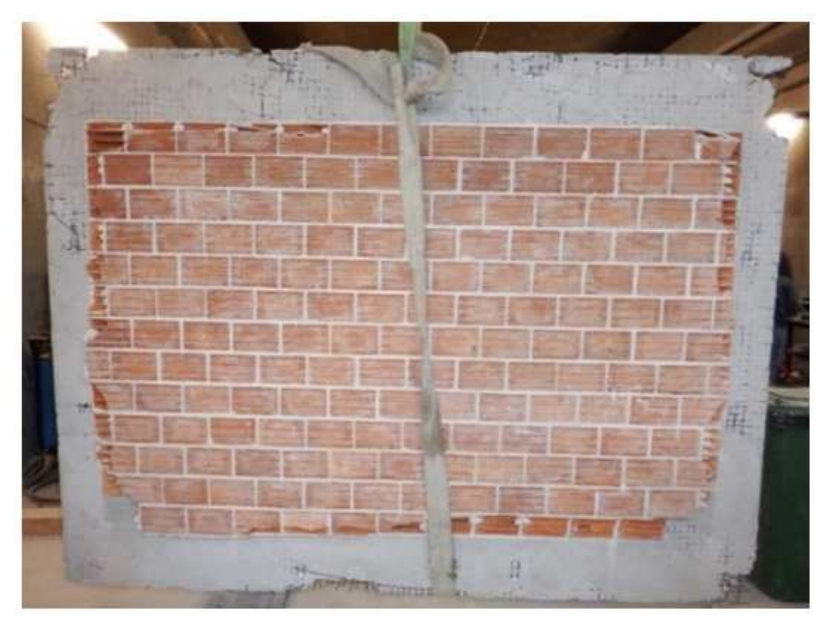

Fig. 3: View of the crushing of bricks of the infill after removing some parts of the retrofitting layer, taken from Akhoundi et al. (2018)

We want to thank all the DCEE2017 participants, the authors of this special issue for their profitable contributions and the reviewers who carefully read the manuscripts and contributed to the improvement of the submitted articles

\section{References}

Akhoundi, F., G. Vasconcelos and P. Lourenço, 2018. Inplane behavior of infills using glass fiber shear connectors in Textile Reinforced Mortar (TRM) Technique. Int. J. Struct. Glass Adv. Mat. Res., 2: 1-14. DOI: $10.3844 /$ sgamrsp.2018.1.14

Baraldi, D., F. Minghini, E. Tezzon and N. Tullini, 2018. Nonlinear analysis of RC box culverts resting on a linear elastic soil. Int. J. Struct. Glass Adv. Mat. Res., 2: 30-45. DOI: 10.3844/sgamrsp.2018.30.45
Casapulla, C., A. Maione and L.U. Argiento, 2018. Infrared thermography for the characterization of painted vaults of historic masonry buildings. Int. J. Struct. Glass Adv. Mat. Res., 2: 46-54. DOI: $10.3844 /$ sgamrsp.2018.46.54

Concu, G., N. Trulli and M. Valdes, 2018. Knowledge acquisition of existing buildings by means of diagnostic surveying. Case Studies. Int. J. Struct. Glass Adv. Mat. Res., 2: 22-29. DOI: $10.3844 /$ sgamrsp.2018.22.29

Deligia, M., F. Pittau, S. Corda, M. Serra and M. Sassu, 2018. A didactical laboratory of structural engineering for bachelor civil engineering students in Cagliari. Int. J. Struct. Glass Adv. Mat. Res., 2: 73-81. DOI: 10.3844/sgamrsp.2018.73.81

Froli, M. and F. Laccone, 2018. HYGLASS: Design proposal for an integrated multifunctional hybrid glass-steel structure. Int. J. Struct. Glass Adv. Mat. Res., 2: 15-21. DOI: 10.3844/sgamrsp.2018.15.21

Hussein, M.J., S.S. Hindal and A.A. Awaad, 2018. Preparation of porous silicon p-type and thermal diffusivity measurement using photoacoustic technique. Int. J. Struct. Glass Adv. Mat. Res.

Valdes, M., N. Trulli and B. De Nicolo, 2018. From plastic waste to building material: Mechanical properties of recycled thermoplastic timber. Int. J. Struct. GlassAdv. Mat. Res., 2: 55-65. DOI: $10.3844 /$ sgamrsp.2018.55.65

Zhang, X. and C. Bedon, 2018. Vulnerability and protection of glass windows and facades under blast: Experiments, methods and current trends. Int. J. Struct. Glass Adv. Mat. Res., 1: 10-23. DOI: $10.3844 /$ sgamrsp.2017.10.23

Zucca, M., N. Longarini, F. de Socio and I. Migliori, 2018. Construction stage analysis for a new mixed structure building in Milan. Int. J. Struct. Glass Adv. Mat. Res., 2: 66-72.

DOI: $10.3844 /$ sgamrsp.2018.66.72 